\title{
Cerebral Arteriovenous Malformations with Associated Arterial Aneurysms: Hemodynamic and Therapeutic Considerations
}

\author{
Douglas Kondziolka, Bruce J. Nixon, Pierre Lasjaunias, William S. Tucker, \\ Karel TerBrugge and Sanford M. Spiegel
}

\begin{abstract}
The common vascular anomalies of cerebral aneurysm and arteriovenous malformation may exist independently, or together as part of a closely related hemodynamic pairing. Resection or embolization of an AVM may be followed by a decrease in local blood flow, and lead to regression of a suitably situated proximal aneurysm. However, aneurysms located outside the angioarchitecture of the AVM, which remain flow-unrelated to the malformation, will likely not regress, and may in fact enlarge. Two cases are presented which demonstrate these vascular relationships, in order to better understand the regional hemodynamics of these anomalies prior to surgical or endovascular treatment planning.
\end{abstract}

\begin{abstract}
RÉSUMÉ: Anévrismes arteriels associés à des malformations artério-veneuses cérébrales L'anévrisme cérébral et la malformation artério-veineuse sont des anomalies vasculaires fréquentes qui peuvent se rencontrer isolément ou ensemble, couplées dans une relation hémodynamique étroite. La résection ou l'embolisation d'une malformation artério-veineuse peut entraîner une diminution du flot sanguin local et une régression d'un anévrisme situé à proximité. Cependant, les anévrismes localisés hors de l'angio-architecture de la malformation artério-veineuse et dont le flot sanguin n'est pas lié à la malformation, ne régresseront probablement pas. lls peuvent même augmenter de volume. Nous présentons deux cas qui démontrent ces relations vasculaires, afin de mieux comprendre l'hémodynamique régionale de ces anomalies avant de planifier un traitement chirurgical ou endovasculaire.
\end{abstract}

Can. J. Neurol. Sci. 1988; 15:130-134

Concurrent association between saccular aneurysms and cerebral arteriovenous malformations (AVM's) is well reported. 1-19 Aneurysms are present in approximately $2.7 \%$ to $14 \%$ of patients with AVM's; ${ }^{6,11,14,18} 37 \%$ of these are located on a major feeding artery to the malformation as reported in the Co-operative study. 15

The etiology of these aneurysms is most likely due to abnormal hemodynamic stresses in the parent artery; this hypothesis is supported by the disappearance of these aneurysms after altering the hemodynamics of blood flow in the parent vessel either by surgical removal, ${ }^{10,17,20}$ or by spontaneous regression of the AVM. ${ }^{21}$ Others have suggested that aneurysmal formation may be a coincidental finding, ${ }^{7}$ or secondary to some underlying generalized vascular pathology. ${ }^{2,4}$

Important management questions are raised in the care of these patients. With the clinical presentation of hemorrhage, one must decide which anomaly was the culprit. The risk of hemorrhage from the aneurysm is apparently higher than the risk of hemorrhage from the distal AVM ${ }^{15}$ Batjer et al reported their series of nine patients with subarachnoid hemorrhage harbouring both an aneurysm and an AVM - seven patients bled from the proximal aneurysm, the other two from the AVM ${ }^{16}$ In selected cases, proximity of the hematoma to the specific anomaly may make the decision an easy one. However, this frequently is not the case, especially in AVM's causing subarachnoid hemorrhage, or with aneurysm related intraparenchymal hematomas.

The interventional question as to which anomaly to treat, and in what order, is raised. Reports of aneurysmal contraction or disappearance after AVM resection alone have been made. ${ }^{9,17,18}$ However there is evidence to suggest that certain aneurysmAVM flow relationships may predispose to enlargement of the

From the Divisions of Neurosurgery and Neuroradiology, University of Toronto, and Department of Neuroradiology, Bicetre Hospital, Paris, France. Received June 30, 1987. Accepted in final form February 8, 1988.

Reprint requests to: Karel G. TerBrugge, Department of Neuroradiology, Toronto Western Hospital, 399 Bathurst St., Toronto, Ontario, Canada M5T 2S8 
aneurysm after AVM treatment. Two cases are presented to demonstrate these phenomena.

\section{Case Reports}

\section{Patient 1}

This 43-year-old male first presented to his family physician at the age of 8 years complaining of severe bifrontal headaches. A diagnosis of migraine was made and symptomatic treatment was begun. At the age of 10 years, he experienced his first grand mal seizure. With anticonvulsant therapy, his seizure frequency diminished to one per year, and by the age of 25 , he had no subsequent grand mal episodes, being left with occasional complex partial seizures. Due to a recent increase in seizure frequency, he sought an additional neurological opinion. His clinical examination was normal, but a CT scan demonstrated an AVM in the right frontal lobe, confirmed by angiography (Figure 1). A right anteromedial frontal gyrus AVM was demonstrated. An aneurysm was noted at the origin of the feeding artery to the AVM, from the main trunk of the callosomarginal artery. The AVM drained through a single channel into the medial frontal vein and subsequently to the superior sagittal sinus.

In this patient with no history of hemorrhage and who was neurologically intact, it was elected to treat the AVM by endovascular embolization. Superselective catheterization of the feeding artery was performed using a calibrated leak balloon system. One millilitre of $50 \mathrm{mg} / \mathrm{ml}$ sodium amytal was injected into the feeding artery of the AVM without production of functional deficit. The AVM was then embolized with 0.4 $\mathrm{ml}$ of Isobutyl-2-cyanoacrylate (IBCA). Emboli were deposited both in

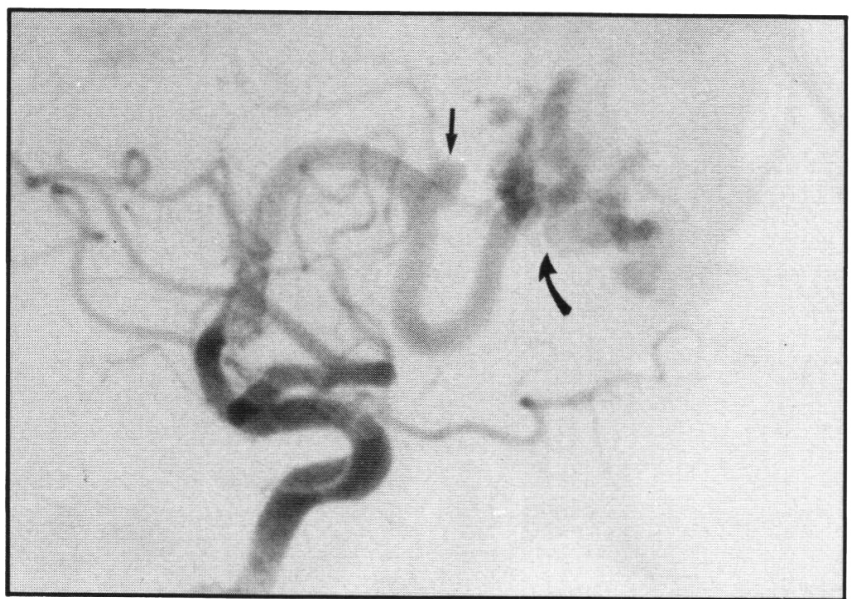

Figure I - Right internal carotid angiogram showing the frontal $A V M$ and a proximal aneurysm at the bifurcation of the callosomarginal artery (patient l).

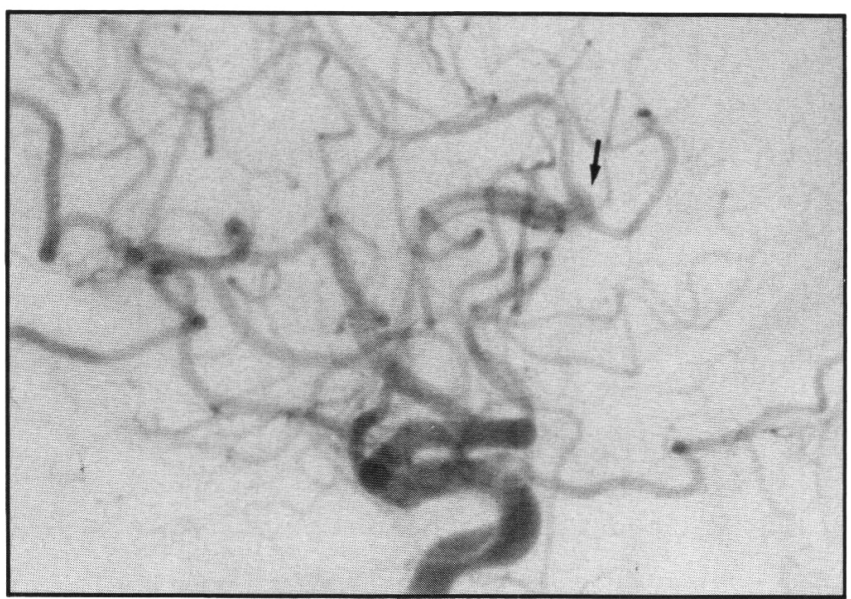

Figure 2 - Angiogram three months post-embolization, showing complete occlusion of the AVM and regression of the proximal aneurysm. the venous ectasia on the edges of the fistula and in the feeding artery. Post-embolization, the systolic blood pressure was controlled and maintained below $110 \mathrm{~mm} \mathrm{Hg}$ for 24 hours with intravenous nitroprusside. The patient was neurologically intact immediately post-embolization and has remained so one year later. His seizures persist but with much decreased frequency.

At three months post-embolization, follow-up angiography showed complete occlusion of the AVM with regression of the proximal aneurysm (Figure 2). The left internal carotid arteriogram was normal. Retrograde thrombosis of the feeding artery was noted to extend to the previous aneurysmal dilatation. At one year follow-up, the patient continues to remain angiographically stable.

\section{Patient 2}

This forty-year-old bisexual male presented to our institution after sudden onset of left hemiplegia. There was a recent diagnosis of Acquired Immune Deficiency Syndrome Related Complex (A.R.C.) but he had suffered no prior neurological or hematological disorder. There was no history of headache, nausea or recent infection. He had mild untreated hypertension, but was normotensive on admission. Examination disclosed an alert man with an almost complete left hemiplegia with some preservation of distal upper limb power. There were no signs of increased intracranial pressure.

Computed tomography (CT) of the brain disclosed a linear hemorrhage in the right parietal lobe above the corpus callosum (Figure 3 ). Cerebral angiography showed the etiology of this hematoma to be a small AVM supplied by a terminal branch of the right pericallosal artery (Figure 4). He also had a $2 \mathrm{~mm}$ aneurysm of the anterior communicating artery which was felt to be clinically unrelated to the presenting hemorrhage. After two days, he underwent craniotomy for removal of his hematoma and resection of his AVM which was performed uneventfully. Postoperatively he demonstrated a complete left hemiplegia including the distal upper extremity, presumed due to retraction.

Five days later, when repeat angiography was performed, the proximally located aneurysm had increased in size. The AVM had been completely resected (Figure 5). Craniotomy for repair of the aneurysm was then performed. He continues to do well postoperatively with progressive improvement of left limb power.

\section{DISCUSSION}

In both cases, specific treatment of the AVM was undertaken prior to treatment of the aneurysm. This was performed, because the AVM was thought to be the clinically significant anomaly, in both cases.

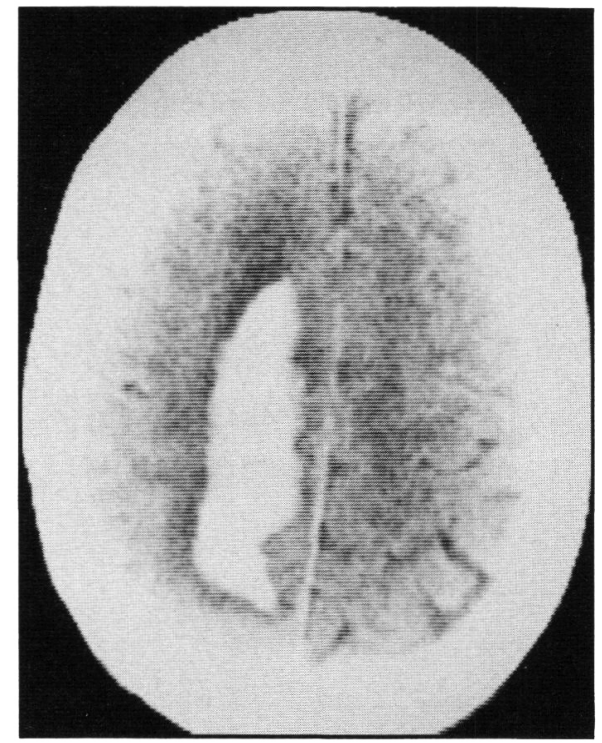

Figure $3-C T$ scan demonstrating a linear hemorrhage in the right parietal lobe above the corpus callosum (patient 2). 
Batjer et al suggested that a sudden increase in vascular resistance associated with an abrupt elimination of an AVM places a proximal aneurysm on the feeding artery at an immediate risk of distension due to further pressure increases and possible subsequent rupture. ${ }^{6}$ They suggested that proximal aneurysms should be treated prior to treatment of arteriovenous malformations. A proximal posterior cerebral artery aneurysm, proximal to an occipital arteriovenous malforma-

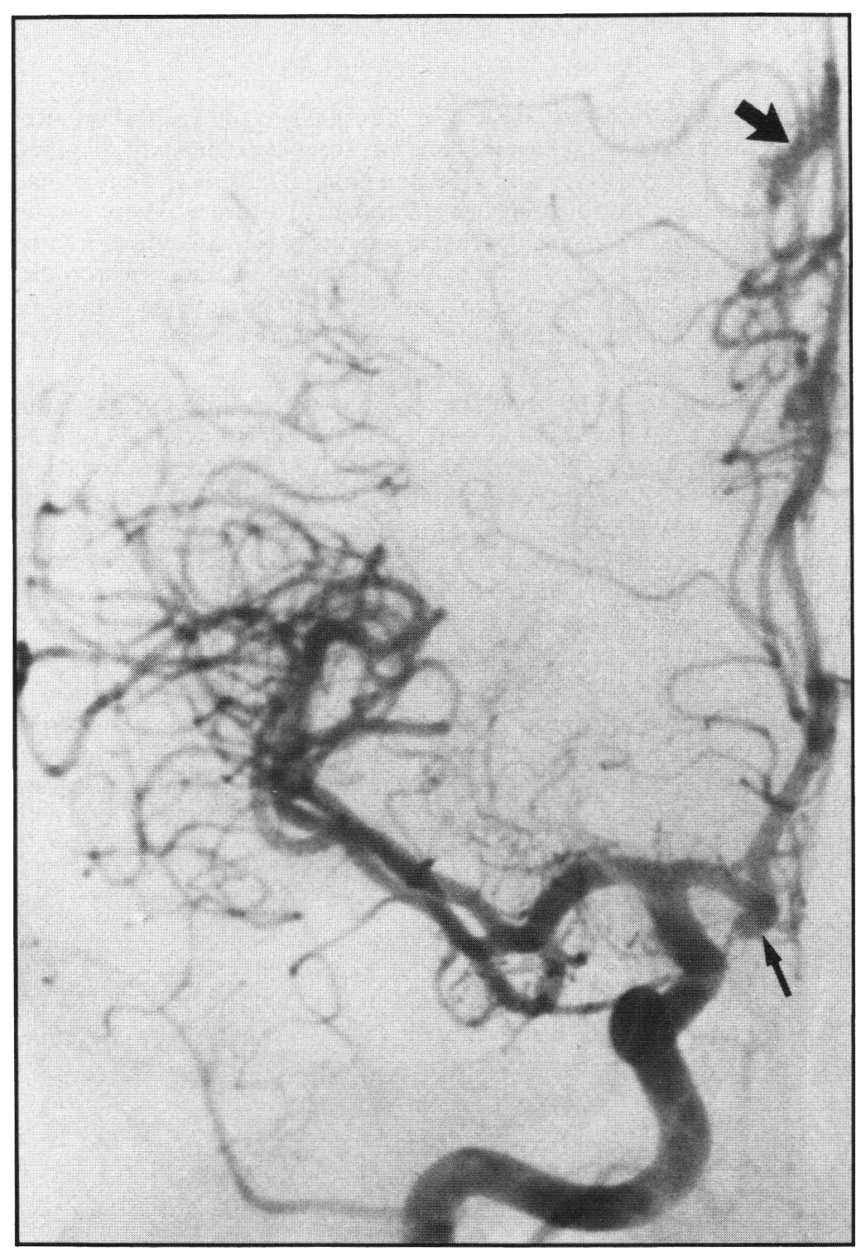

A

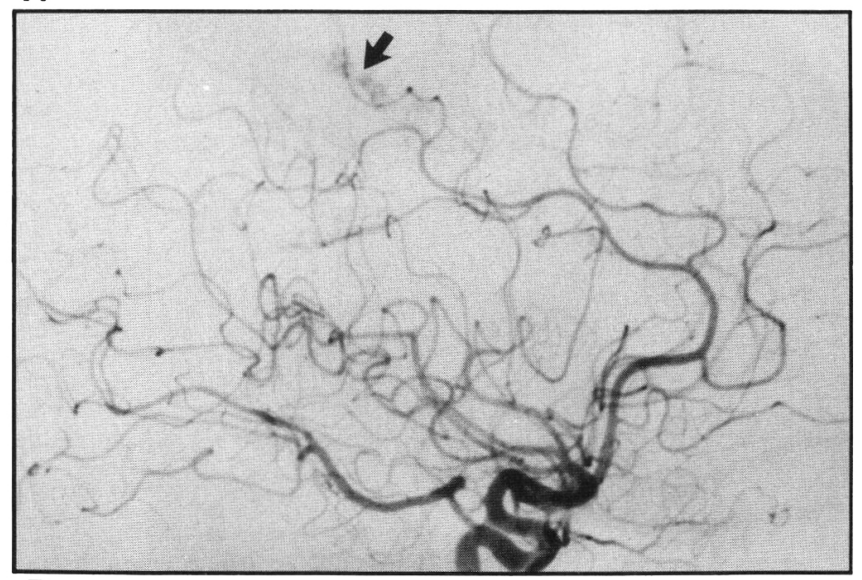

B

Figure 4 - Right internal carotid angiogram (AP \& Lat.) showing a small distal pericallosal AVM (arrow) and an associated aneurysm of the anterior communicating artery (thin arrow). tion has even been embolized using endovascular techniques (G. Hieshima, Scientific Exhibit Symposium Neurologicum, Stockholm, Sweden 1986). As illustrated by case one, and in the experience of others, ${ }^{10,17,20}$ we feel that the abrupt elimination of an AVM puts no greater stress on the proximal aneurysm. It is our opinion that the etiology of these aneurysms is secondary to abnormal patterns of flow into the parent vessel causing abnormal jets of blood to produce an aneurysmal dilatation
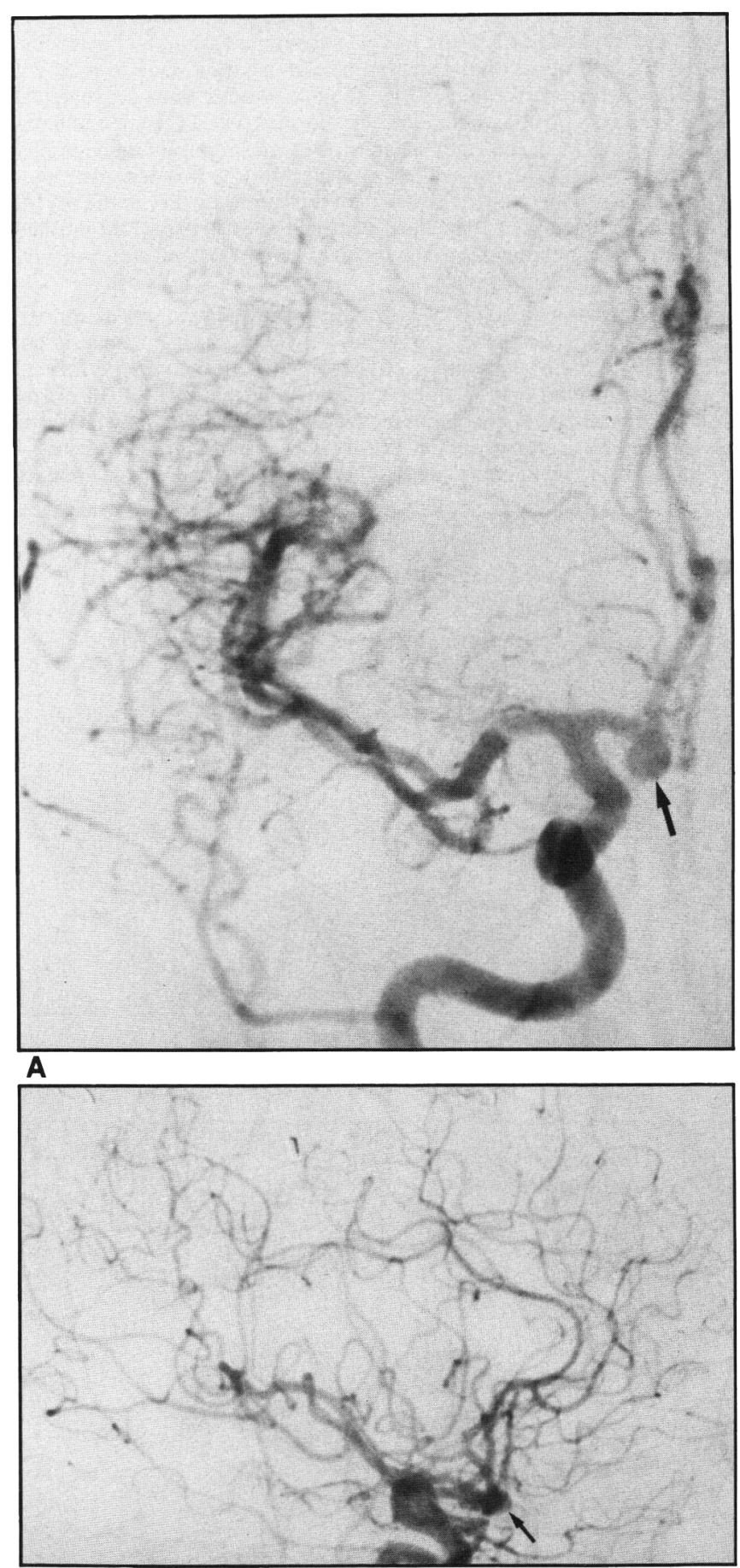

B

Figure 5-Post-operative angiogram shows enlargement of the anterior communicating artery aneurysm after resection of the AVM (arrow). 
along the vessel wall. Once the normal flow pattern has been reinstituted, and the flow redirected away from the AVM (by elimination of the AVM), the jet effect on the aneurysm will be eliminated. The aneurysm will subsequently regress and disappear. Several studies have demonstrated aneurysmal regression secondary to decreased flow, ${ }^{20}$ after surgical resection of a distal $\mathrm{AVM}^{10,17,20}$ and spontaneous involution of an AVM. ${ }^{21.22}$ High energy focal irradiation of an AVM may also promote regression of a proximal aneurysm. ${ }^{23}$ Embolization of the AVM to treat both the AVM directly and the aneurysm indirectly has been successful in this case.

However, not all aneurysms associated with brain AVM's have the same significance and therefore do not require the same treatment. We have noted three types of aneurysms associated with AVM's. ${ }^{8,12}$ The dysplastic aneurysms not associated with a feeding artery, but present in association with an AVM should be treated prior to the AVM, if elimination of the arteriovenous shunt will cause increased hemodynamic stress on the parent artery of the aneurysm. Two other types of aneurysms, one located proximal to the AVM and the other within the nidus can be treated during embolization of the AVM. The proximal aneurysm will be eliminated after embolization or resection of the AVM, as is the case with the patient reported here. The intralesional aneurysms should be treated at the time of the embolization by filling the aneurysm and the AVM with IBCA. If an AVM has multiple feeder vessels, then those feeding arteries with either proximal aneurysms or intralesional aneurysms associated must be embolized first. We do not advocate direct embolization of proximal aneurysms, into which IBCA may be lost and migrate distally into functional brain. Proximal aneurysms rather should be treated by decreasing proximal flow to the resected or embolized AVM.

In our second case, a proximal anterior communicating artery aneurysm is demonstrated many branch points away from a small pericallosal AVM. The two anomalies are unlikely to be flow-related. As a result, treatment of the AVM (via either a surgical or endovascular approach) should not result in a change in aneurysm size. Certainly retrograde thrombosis from the distal pericallosal artery to the anterior communicating artery would not occur and lead to regression of the aneurysm. As noted in this patient, the aneurysm enlarged immediately after resection of the AVM. A number of theories are postulated to explain this.

Aneurysmal enlargement is explained by increased flow or increased pressure within the aneurysm, or by reduction in pressure external to the aneurysm. Experimentally induced cerebral aneurysms in rats have been made by altering the hemodynamics of the circle of Willis. ${ }^{24}$ Spetzler's theory of Normal Perfusion Pressure Breakthrough (NPPB) assumes that vessels proximal to an AVM remain in a maximally dilated state to maintain appropriate blood flow to regional brain tissue. ${ }^{25}$ This would seem necessary to direct needed flow away from the low pressure venous channels of the AVM. As AVM resection proceeds, an enlarging perfusion front is transferred to the proximal vasculature, which would normally be protected by arteriolar constriction. It is therefore thought that uncommon but observed instances of edema or hemorrhage are the results of absent vasoconstriction due to non-autoregulation. A similar phenomenon has been observed with intracerebral hemorrhage after carotid endarterectomy. ${ }^{26}$ Focal cerebral edema in the setting of acute hypertension is also reported. ${ }^{27}$ Possibly, increased pressure could enlarge a related proximal aneurysm.
It is unlikely that NPPB theory pertains to our second patient, as such a small AVM would likely exhibit minimal regional flow effects. We hypothesize that a combination of the craniotomy procedure and evacuation of the intracerebral hemorrhage, led to a decrease in local CSF pressures around the aneurysm and led to its corresponding enlargement.

In patients harbouring both a cerebral aneurysm as well as an arteriovenous malformation, two main clinical problems arise. Firstly, is the clinical syndrome secondary to the AVM, the aneurysm, or both? It should be easy to distinguish the separate compressive effects of each anomaly, for patients presenting with a symptomatic mass lesion. The distinction in patients presenting with hemorrhage may be difficult. Secondly, which lesion should be treated first? Proximal aneurysms on the main feeding artery or intralesional aneurysms may regress with treatment of the AVM. Flow-related proximal aneurysms remote from the feeding artery are at risk for enlargement or rupture and therefore, consideration should be given to treating these first.

It must be recognized however, that the observations of two patients only begin to try to understand the complex hemodynamic physiology of this disorder. Without an experimental model, we are attempting to understand a dynamic process using the information obtained on static serial arteriograms.

The flow effects on the aneurysm will likely remain the same whether surgical resection or endovascular obliteration of the AVM is undertaken. Surgery offers the potential that both lesions can be treated at the same time. Advances in superselective endovascular embolization techniques have allowed that in some cases, similar results can be achieved in the absence of craniotomy.

\section{ACKNOWLEDGEMENT}

The authors wish to thank Dr. Joseph Bruni, Dr. H. Smythe, and Dr. H. Schutz for patient referral, and Pauline Gough for preparation of the manuscript.

\section{REFERENCES}

1. Aarabi B, Chambers J. Giant thrombosed aneurysm associated with an arteriovenous malformation. J Neurosurg 1978; 49: 278-282.

2. Anderson $R, B$ lackwood $W$. The association of arteriovenous angioma and saccular aneurysm of the arteries of the brain. J Path Bacteriol 1959; 77: 101-110.

3. Arai H, Sugiyama $Y$, Kawakami $S$, et al. Multiple intracranial aneurysms and vascular malformations in an infant. J Neurosurg 1972; 37: 357-360.

4. Arieti S, Gray EW. Progressive multiform angiosis: Association of a cerebral angioma, aneurysms and other vascular changes in the brain. Arch Neurol Psych 1944; 51 : 182-189.

5. Batjer H, Samson D. Arteriovenous malformations of the posterior fossa: Clinical presentation, diagnostic evaluation, and surgical treatment. J Neurosurg 1986; 64: 849-856.

6. Batjer H, Suss R, Samson D. Intracranial arteriovenous malformations associated with aneurysms. Neurosurgery $1986 ; 18: 29-35$.

7. Boyd-Wilson JS. The association of cerebral angiomas with intracranial aneurysms. J Neurol Neurosurg Psychiatry 1959; 22: 218-233.

8. Cronqvist $S$, Troupp $H$. Intracranial arteriovenous malformation and arterial aneurysm in the same patient. Arch Neurol Scandinav 1966; 42: 307-316.

9. Drake CG. Surgical removal of arteriovenous maiformations from the brain stem and cerebellopontine angle. J Neurosurg 1975; 43: 661-670.

10. Hayashi $S$, Arimoto $T$, Itakura $T$, et al. The association of intracranial aneurysms and arteriovenous malformation of the brain. Case report. J Neurosurg 1981; 55: 971-975. 
11. Higashi K, Hatano M Yamashita T, et al. Coexistence of posterior inferior cerebellar artery aneurysm and arteriovenous malformation fed by the same artery. Surg Neurol 1979; 12: 405-408.

12. Lasjaunias P, Manelfe C, Chiu M. Angiographic architecture of intracranial arteriovenous malformations and fistulas - pretherapeutic aspects. Neurosurg Rev 1986; 9 (4): 253-263.

13. McCormick, WF, Hardman JM, Boulter TR. Vascular malformation of the brain with special reference to those occurring in the posterior fossa. J Neurosurg 1968; 28: 241-251.

14. Paterson JH, McKissock W. A clinical survey of intracranial angiomas with special reference to their mode of progression and surgical treatment: A report of 110 cases. Brain 1956; 79: 233-266.

15. Perret G, Nishioka H. Report on the Cooperative study of intracranial aneurysms and subarachnoid hemorrhage. Section VI Arteriovenous malformations. J Neurosurg 1966; 25: 467-490.

16. Reigh EE, Lemen LJ. Cerebral aneurysms with other intracranial pathology. J Neurosurg 1960; 17: 469-476.

17. Shenkin HA, Jenkins F, Kim K. Arteriovenous anomaly of the brain associated with cerebral aneurysm. J Neurosurg 1971; 34: 225-228.

18. Suzuki J, Onuma T. Intracranial aneurysms associated with arteriovenous malformations. J Neurosurg 1979; 50: 742-746.

19. Walsh FB, King AB. Occular signs of intracranial saccular aneurysms. Experimental work on collateral circulation through the ophthalmic artery. Arch Ophthalmol 1942; 27: 1-33.
20. Kouloris S, Rizzoli HV. Coexisting intracranial aneurysm and arteriovenous malformation: Case report. Neurosurgery 1981; 8: 219-222.

21. Takara $\mathrm{E}$, Inoue $\mathbf{N}$, Kohno $\mathrm{H}$. (Disappearance of the co-existing aneurysm and arteriovenous malformation after wrapping of aneurysm.) No Shinkei Geka 1980; 8: 587-591.

22. Omojole MF, Fox AJ, Vinuela F, et al. Stenosis of efferent vessels of intracranial arteriovenous malformations. Amer J Neuroradiol 1985; 6: 791-793.

23. Kjellberg RN, Hanamura $\mathrm{T}$, Davis $\mathrm{K}$, et al. Bragg peak proton beam therapy for arteriovenous malformations of the brain. New Eng J of Med 1983; 309: 269-274.

24. Hashimoto N, Handa H, Nagata I, et al. Experimentally induced cerebral aneurysms in rats: Part V. Relation of hemodynamics in the circle of Willis to formation of aneurysms. Surg Neurol 1980; 13: $41-45$.

25. Spetzler RF, Wilson $C B$, Weinstein $P$, et al. Normal perfusion pressure breakthrough theory. Clin Neurosurg 1977;25:651-672.

26. Bernstein M, Fleming JFR, Deck JHN. Cerebral hyperperfusion after carotid endarterectomy: A cause of cerebral hemorrhage. Neurosurgery $1984 ; 15: 50-56$.

27. Hatachita $S$, Hoff JT Ishii $S$. Focal brain edema associated with acute arterial hypertension. J Neurosurg 1986; 64: 643-649. 